\title{
Expression and Degradation of SEp22, a Pathogenicity-Related Protein of Salmonella Dps, in Salmonella enterica serovar Enteritidis Isolated from the Poultry Farms in Japan
}

\author{
Shiori Teral ${ }^{1}$, Manabu YAMASAKI ${ }^{2}$, Shizunobu IGIMI ${ }^{2}$ and Fumio AMANO ${ }^{1 *}$ \\ ${ }^{1}$ Laboratory of Physiological Chemistry, Osaka University of Pharmaceutical Sciences, 4-20-1 Nasahara, Takatsuki, Osaka 569- \\ 1094, Japan \\ 2Division of Biomedical Food Research, National Institute of Health Sciences, 1-18-1 Kamiyoga, Setagaya-ku, Tokyo 158-8501, Japan
}

Received July 29, 2005; Accepted for publication, September 6, 2005

\begin{abstract}
We isolated and characterized a pathogenicity-related protein in Salmonella enterica serovar Enteritidis (SE) from poultry farms, and designated it as SEp22, which has recently been identified with Salmonella Dps, a DNA-binding protein (12, 13, Amano et al., manuscript in preparation). Expression of SEp22 was shown to be transcriptionally regulated, because another SE strain without virulence was found to possess a full-length non-mutated gene of sep22, but had little expression of SEp22 mRNA and much lower levels of SEp22 protein compared to the virulent standard strain SE CI\#15-1. Besides, expression of SEp22 was connected with bacterial growth, showing reduced expression in the logarithmic phase but increased expression from the late logarithmic to stationary phases. These changes were slightly later than those in $\sigma^{38}$ levels as well as SEp22 mRNA, suggesting that expression of SEp22 is under transcriptional control through RNA polymerase activity by $\sigma^{38}$. In addition, high levels of SEp22 in the stationary phase were rapidly reduced upon incubation of the bacteria in fresh medium. This reduction was dependent on bacterial concentration in the culture, temperature, and time of incubation, suggesting proteolytic degradation of SEp22 in growing bacteria.
\end{abstract}

Key words: Salmonella enterica serovar Enteritidis; Dps; growth phase; pathogenicity; transcriptional control

\section{INTRODUCTION}

Salmonella enterica serovar Enteritidis (SE) has been one of the most causative bacteria of food-borne diseases in Japan. Poultry is an important source for spreading SE, not only thorough food but also through environmental contamination (2). Epidemiological studies have revealed that the major vehicles of SE outbreaks in humans have included contaminated poultry meat and eggs (5). In our previous studies searching for factors and mechanisms underlying acquisition by environmental SE of pathogenicity to the mouse, we identified and characterized a pathogenicity-related protein of MW, of approximately $22 \mathrm{kDa}$, in SE isolated from poultry farms and designated it as SEp22. We analyzed sequences of $N$-terminal 22 amino acids of SEp22, and performed cloning of the sep22 gene covering full length coding of nucleotide sequences corresponding to 168 amino acids. The sep22 gene was shown to be similar to E. coli dps/ pex $B$, and subsequently to be identical to Salmonella dps (7). We also constructed sep22-defective Salmonella

*Corresponding author. Mailing address: Laboratory of Physiologica Chemistry, Osaka University of Pharmaceutical Sciences, 4-20-1 Nasahara, Takatsuki, Osaka 569-1094, Japan. Phone: + 81-72-6901054. Fax:+81-72-690-1054. E-mail: amano@gly.oups.ac.jp mutants and examined the correlation between expression of SEp22 and pathogenicity to BALB/c mice using these mutants together with the wild-type parental strain $(12,13$, Amano et al., manuscript in preparation). In the course of our study on SEp22, Halsey et al. reported the involvement of Salmonella Dps in the pathogenicity of Salmonella infection in a gene-targeting study (7). However, regulation of SEp22 expression especially with respect to virulence of environmental isolates remains largely unknown. In this study, we show that the assessment of pathogenicity of Salmonella requires analysis of SEp22 at mRNA or protein level, because analysis at the gene level is insufficient and expression of SEp22 is transcriptionally regulated. Moreover, we show that SEp22 levels are regulated by bacterial growth not only in induction of the transcription and translation through the logarithmic to stationary phases, but also in the breakdown of the SEp22 protein in fresh medium, where it depends on bacterial concentration, and incubation time and temperature under growing conditions in the early logarithmic phase.

\section{MATERIAL AND METHODS}

Bacterial culture

Salmonella enterica serovar Enteritidis strains SE 
Cl\#15-1 and SE Cl\#16-1, obtained from CAF Laboratories (Fukuyama, Hiroshima, Japan), were used in this study. The bacteria were cultured in $100 \mathrm{ml}$ of Luria-Bertani (LB) medium (Difco ) in 300-ml Erlenmeyer flasks at $37^{\circ} \mathrm{C}$ overnight, with shaking at 150 strokes $\mathrm{min}^{-1}$. They were harvested by centrifugation at $3,500 \mathrm{rpm}$ for $20 \mathrm{~min}$ (Tomy EX-125) at $4^{\circ} \mathrm{C}$, and were regrown in $15 \mathrm{ml}$ of fresh $\mathrm{LB}$ in $50-\mathrm{ml}$ tubes at $37^{\circ} \mathrm{C}$ for 1 $\mathrm{hr}$, with shaking as above. Incubation was terminated by chilling on ice, and the cells were harvested by centrifugation. The cells were washed twice with icecold phosphate-buffered saline (PBS), $\mathrm{pH} 7.5$, and were suspended in PBS until use. For quantitative analysis of SEp22 by SDS-PAGE/western blotting, different sets of Elrenmeyer flask cultures were prepared for each time point to obtain sufficient numbers of bacteria; the initial volume and concentration of bacteria in each flask were equal among the cultures, but the bacteria in the logarithmic phase were harvested from 2-4 flasks for each time point, while those in the stationary phase, from one.

\section{Preparation of bacterial cell extracts}

The washed cells were disrupted with $0.1 \mathrm{~g}$ of glass beads (Sigma) in a cell beater (BIO 101 Savant, Fast Prep $^{\mathrm{TM}}$ FP120) and centrifuged at $15,000 \mathrm{rpm}$ for $5 \mathrm{~min}$ at $4{ }^{\circ} \mathrm{C}$. The resultant supernatant was collected as bacterial cell extract. Aliquots of the cell extracts containing the same amounts of protein were subjected to SDS-PAGE followed by western blot analysis. Protein concentrations of the cell extracts were determined with the Protein assay reagent (Bio-Rad) with bovine serum albumin as a standard.

\section{SDS-PAGE/western blotting}

SE extracts of the same protein amount were loaded on $5-20 \%$ polyacrylamide Slab gels (e-PAGEL ${ }^{\mathrm{TM}}$; ATTO, Tokyo), and electrophoresis was performed according to the discontinuous buffer system of Laemmli (9). After electrophoresis, the separated proteins were electrotransferred to PVDF membranes (Immobilon $\mathrm{P}^{\mathrm{TM}}$; Millipore), which were blocked with $30 \mathrm{mg} \mathrm{ml}^{-1}$ milk casein (Snow Brand, Sapporo, Japan) in the rinse buffer $(0.1 \%$ Triton X-100 in 10 mM Tris-HCl, 0.1 mM EDTA, $0.8 \% \mathrm{NaCl}, \mathrm{pH} 7.5$ ), then reacted with a polyclonal antiSEp22 antibody raised in rabbits, anti- $\sigma^{38}$ or anti- $\sigma^{70}$ antibody ( generously donated by Dr. Akira Ishihama, The National Institute of Genetics) at $37^{\circ} \mathrm{C}$ for $2 \mathrm{hrs}$. The membrane was washed three times with the rinse buffer and incubated with HRP-conjugated anti-rabbit IgG (Cell Signaling) for $1 \mathrm{hr}$ at room temperature. Finally, immune complexes on the membrane were reacted with luminol and $\mathrm{H}_{2} \mathrm{O}_{2}$, according to the manufacture's protocol (Cell Signaling).

\section{Quantitative analysis of SEp22}

Quantitation of chemiluminescence associated with each protein was performed by a LAS 1000 bioimage analyzer (Fuji Film) and the image was analyzed with Multi Gauge software (version 2.2; Fuji Film). For estimation of the levels of SEp22 in each cell extract, the quantitative determination was repeated at least three times with independent cell extracts from different experiments.

Sequence analysis of sep22 gene

To amplify the sep 22 gene with its putative promoter region from SE genomic DNAs, the following PCR primers were designed from the flanking sequence of the $d p s$ gene of Salmonella enterica serovar Typhimurium: 5'-ATGCAGAATATCACCTCGTT-3' as a forward primer and 5'-GAGGGGAGTACAAGACGTG-3' as a reverse primer. PCR conditions with $L A T a q$ polymerase (TaKaRa) were $95^{\circ} \mathrm{C}$ for 2 min, followed by 25 cycles of $95^{\circ} \mathrm{C}$ for $30 \mathrm{~s}, 55^{\circ} \mathrm{C}$ for $30 \mathrm{~s}$, and $72^{\circ} \mathrm{C}$ for $1.5 \mathrm{~min}$, and a final extension at $72^{\circ} \mathrm{C}$ for $10 \mathrm{~min}$. The PCR product of the expected size ( $972 \mathrm{bp}$ ) was subjected to direct sequencing (SciMedia; Tokyo) by using the same primers used in the PCR amplification and the following two additional primers: 5'-AGTTGCTTAATCGTCAGGT-3' and 5'-CTAACGCCACACCGCCAA-3'.

\section{RNA extraction and northern blot analysis}

Total RNA was isolated from SE cells at different time points of growth by resuspending them in TRIzol reagent (Invitrogen) and sonicating for $5 \mathrm{~min}$ at $200 \mathrm{~W}$. It was then subjected to purification using the SV Total RNA Isolation System (Promega), incorporating DNase treatment. Total RNA samples $(1.5$ or $2 \mu \mathrm{g})$ were separated in a non-denaturing 1.3\% agarose gel using DynaMakerRNA Easy Measurement N (BioDynamics Laboratory Inc., Tokyo). Transfer of separated RNAs to a positively charged nylon membrane (BrightStar-Plus: Ambion, Inc., Texas, USA) and hybridization with a probe were performed using the NorthernMax ${ }^{\mathrm{R}} \mathrm{Kit}$ (Ambion) according to the manufacturer's instructions. The DNA probe was prepared by PCR amplification of a 459 bp $d p s$ fragment using the primer set 5'AAAACAAAAGCGTCTAATCT-3' and 5'CCACAGGAATTTATCGAGGT-3', and labeled with Biotin (BrightStar ${ }^{\mathrm{R}}$ Psoralen-Biotin; Ambion). The biotin-labeled probe was detected using the BrightStar ${ }^{\mathrm{R}}$ 
BioDetect ${ }^{\mathrm{TM}}$ Kit (Ambion) according to the manufacturer's instructions, and was visualized by exposure to X-ray film (Fujifilm). The intensity of the $d p s$ band was quantitated relative to that of the EtBrstained 16S rRNA band in the gel before the blotting, using Scion image Beta 4.02.

\section{RESULTS}

\section{Comparison of sep22 gene from different SE clones}

We isolated a variety of SE strains from poultry farms that were either pathogenic or non-pathogenic to BALB/c mice. Among them, we showed that SEp22 (+) killed mice infected orally, while SEp22 (-) strains did not. We suggest that these differences in the virulence of SE strains is closely related to the expression of SEp22 protein (12, 13, Amano et al., manuscript in preparation). In this study, we examined whether there was a difference at the gene level, comparing the sequences of sep 22 gene of SE Cl\#15-1 as a SEp22 (+) strain and that of SE Cl\#161 as a SEp22 (-) strain by PCR cloning. The strains have the same sep 22 gene structure in the coding sequences (data not shown), however, expression of SEp22 mRNA was greatly different between these two clones. The amount of mRNA in SE Cl\#15-1 was more than 6.83 times higher than that in SE Cl\#16-1, based on the northern blot analysis (Fig. 1). Similar results were obtained by semi-quantitative RT-PCR analyses of SEp22 mRNA and 16S rRNA, which showed that the ratio of SEp22 mRNA/ 16S rRNA in SE Cl\#15-1 was

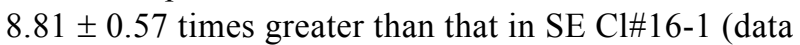
not shown). These results suggest that expression of SEp22 is transcriptionally regulated.

\section{Growth phase-dependent expression of SEp22}

To examine the effects of the proliferation of the bacterium on the appearance of SEp22, we quantitated the amounts of SEp22 protein in Salmonella extracts, together with those of sigma factors $\left(\sigma^{38}\right.$ and $\left.\sigma^{70}\right)$ at different time points in the growth phases. SEp22 decreased soon after the culture in fresh medium started, followed by increase after the bacterial growth entered into the late logarithmic phase with the maximal expression in the stationary phase (Fig.2 A, B). On the other hand, expression of $\sigma^{38}$ also showed cyclic changes similar to SEp22, but always 1-2 hrs in advance of those in SEp22 (Fig. 2B). Unlike those of $\sigma^{38}, \sigma^{70}$ levels remained unchanged throughout the culture (Fig. 2B). Northern blot analysis revealed that increase of SEp22 mRNA always preceded SEp22 protein increase by 1-2 hrs, but SEp22 mRNA began to decrease after the culture entered the stationary phase (Fig. 2C). These results

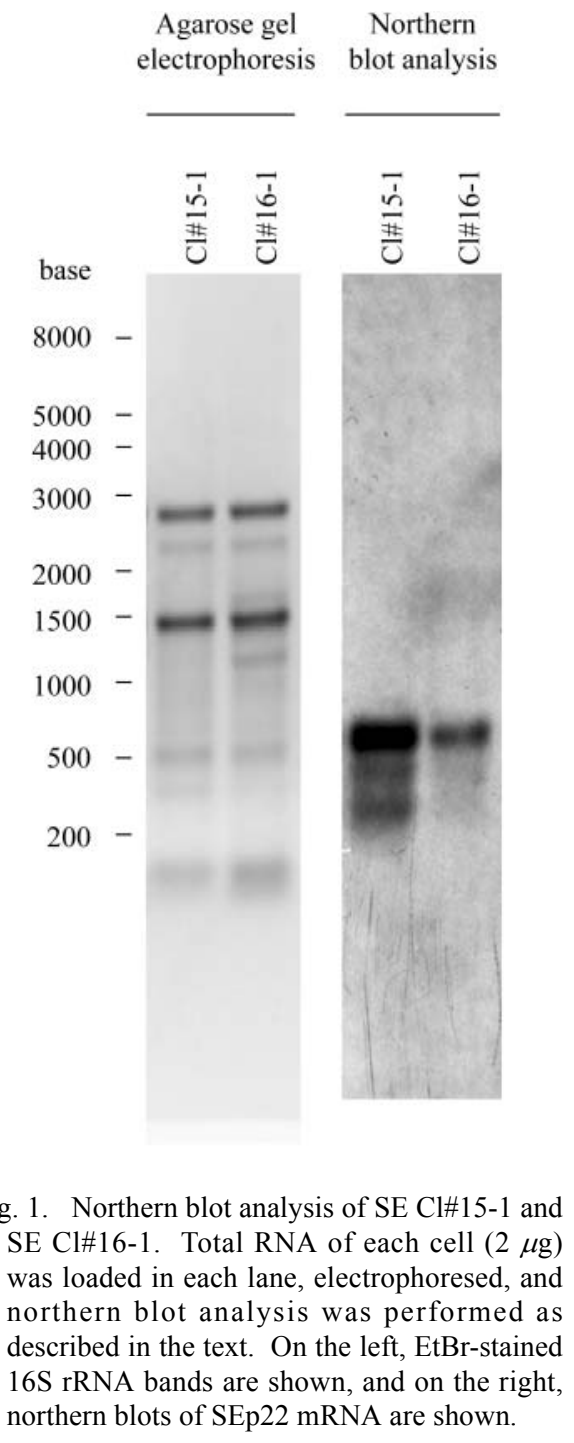

suggest that expression of SEp22 is transcriptionally induced in accordance with the progression of the growth phase to the stationary phase, probably through $\sigma^{38}$.

In addition, it should be noted that SEp22 decreased in the cells very rapidly when stationary phase bacteria were cultured in fresh medium, and it was observed at 2 and again at $26 \mathrm{hrs}$, two hours after bacteria were diluted and transferred to new medium (Fig. 2A). This was not the dilution of the bacterial cell extract loaded on the SDS-gels, but the actual disappearance of SEp22 from the cell extracts in the logarithmic phases, because the same amounts of the cell extracts were loaded, separated and analyzed by SDS-PAGE/western blotting. These results suggest that expression of SEp22 is downregulated post-translationally probably through rapid digestion by protease(s). 
(A)

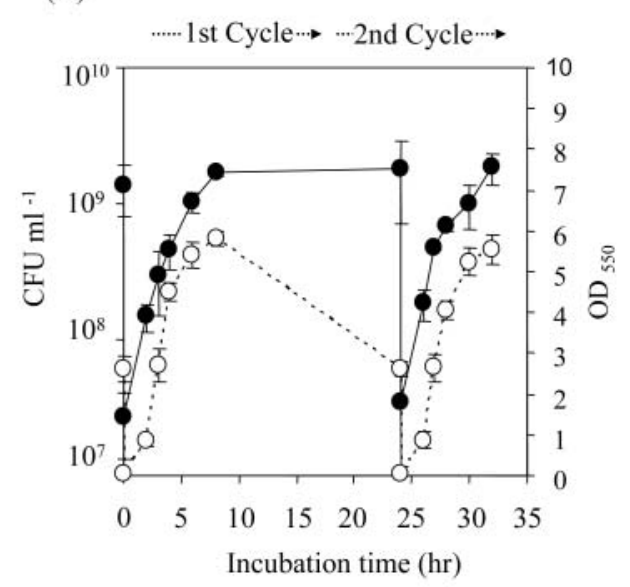

(B)

Incubation time (hr)

$\ldots . . .1$ st Cycle $\rightarrow \cdots 2$ nd Cycle $\rightarrow$

$\begin{array}{lllllllll}0 & 2 & 3 & 4 & 6 & 8 & 242627283032\end{array}$

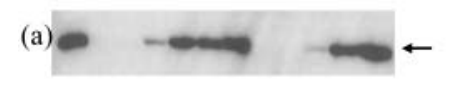

(b)

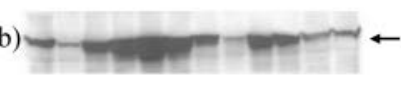

(c)

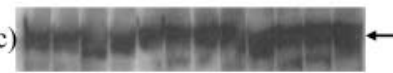

(C)

Incubation time (hr)

....1 1st Cycle $* \cdots$ 2nd Cycle $*$

$\begin{array}{llllllll}0 & 2 & 3 & 4 & 6 & 8 & 242627283032\end{array}$
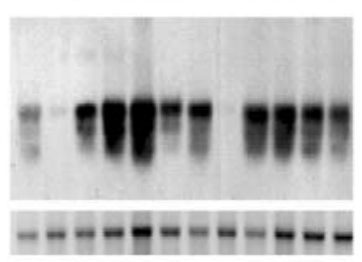

Fig. 2. Growth phase-dependent changes of the expression of SEp22, $\sigma^{38}$ and $\sigma^{70}$ proteins and SEp22 mRNA in SE Cl\#15-1. (A) Growth curve of SE Cl\#15-1 in LB medium. Bacteria numbers are shown as CFU ml ${ }^{-1}(\bullet)$ and $\mathrm{OD}_{550}(\mathrm{O})$. An overnight culture of SE Cl\#15-1 in the stationary phase was diluted and the concentration at $\mathrm{OD}_{550}$ was adjusted to 0.05 with fresh LB medium, followed by incubation of $\mathrm{SE}$ at $37^{\circ} \mathrm{C}$, with shaking at 150 strokes $\min ^{-1}$ (1 st cycle). On the second day, dilution and culture of the bacterium was repeated (2nd cycle). The results are from a representative experiment of three independent ones, and are shown as means \pm SD. (B) Expression of (a) SEp22, (b) $\sigma^{38}$ and (c) $\sigma^{70}$ proteins in SE Cl\#15-1 at different time points in the growth phases are shown at the top of the figure as incubation times (hrs). Western blot analysis was performed with specific antibodies against SEp22, $\sigma^{38}$, or $\sigma^{70}$, following SDS-PAGE of the same amount of each bacterial cell extract, as described in the text. Panels (a), (b) and (c) correspond to the proteins with MW of $19 \mathrm{kDa}$ (SEp22), $38 \mathrm{kDa}$ $\left(\sigma^{38}\right)$ and $70 \mathrm{kDa}\left(\sigma^{70}\right)$, respectively. (C) Expression of SEp22 mRNA (upper panel) and 16S rRNA (lower panel). Equal amounts of total RNA $(1.5 \mu \mathrm{g})$ were loaded in each lane and northern blots of SEp22 mRNA are shown in the upper panel. In the lower panel, the EtBr-stained 16S rRNA bands are shown.

\section{Degradation of SEp22}

As shown in Fig. 2B, SEp22 protein became undetectable in the first $2 \mathrm{hrs}$ after the bacteria started growth in fresh medium, showing rapid degradation of
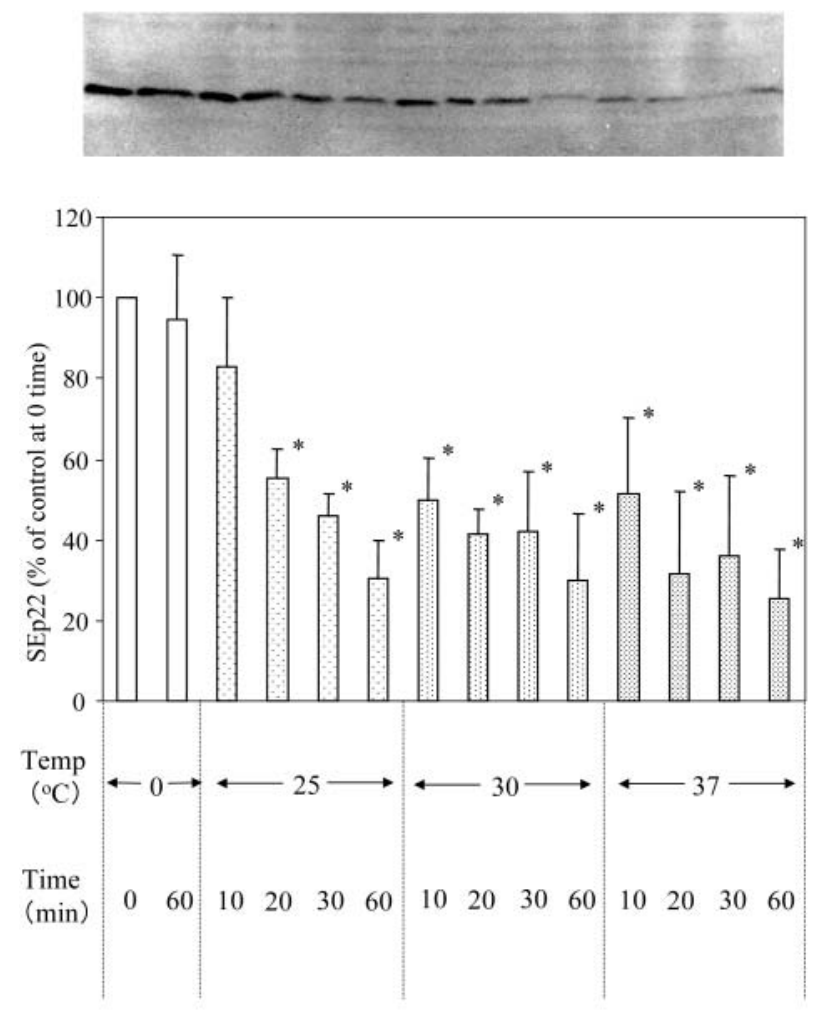

Incubation condition

Fig. 3. Time course of SEp22 degradation in the regrowing cells. $\mathrm{SE}$ Cl\#15-1 cultured overnight was diluted to $\mathrm{OD}_{550}=1.0$ with fresh LB medium followed by incubation at $0,25,30$ or $37^{\circ} \mathrm{C}$ for various times up to $60 \mathrm{~min}$. The growth was stopped by chilling the bacteria on ice, followed by washing with ice-cold PBS and the bacterial cell extracts were prepared as described in the text. Analysis of SEp22 by SDS-PAGE and western blotting was performed as described in the legend to Fig. 2. The upper figure shows a representative result of western blot and the lower one, relative amounts of SEp22 protein analyzed from three independent experiments, shown as means $\pm \mathrm{SD}, * P \leq 0.05$ by Student's $t$-test, compared with the control at $0^{\circ} \mathrm{C}$, at 0 time.

SEp22 took place in the stationary phase. We next focused on the degradation of SEp22 because the regulatory mechanisms of Dps degradation remain largely unknown, especially under physiological conditions. First we examined the time-course of SEp22 degradation. Stationary phase bacteria, cultured overnight, were adjusted a concentration showing $\mathrm{OD}_{550}$ $=1.0$ and recultured in fresh medium at various temperatures for 0-60 min (Fig. 3). The degradation of SEp 22 at $37^{\circ} \mathrm{C}$ proceeded rapidly, within $10 \mathrm{~min}$, while that at $4^{\circ} \mathrm{C}$ showed little change even after $60 \mathrm{~min}$. Changing the incubation temperature to $30^{\circ} \mathrm{C}$ or $25^{\circ} \mathrm{C}$ resulted in slower degradation than that at $37^{\circ} \mathrm{C}$, but SEp22 was still significantly decreased from the initial 


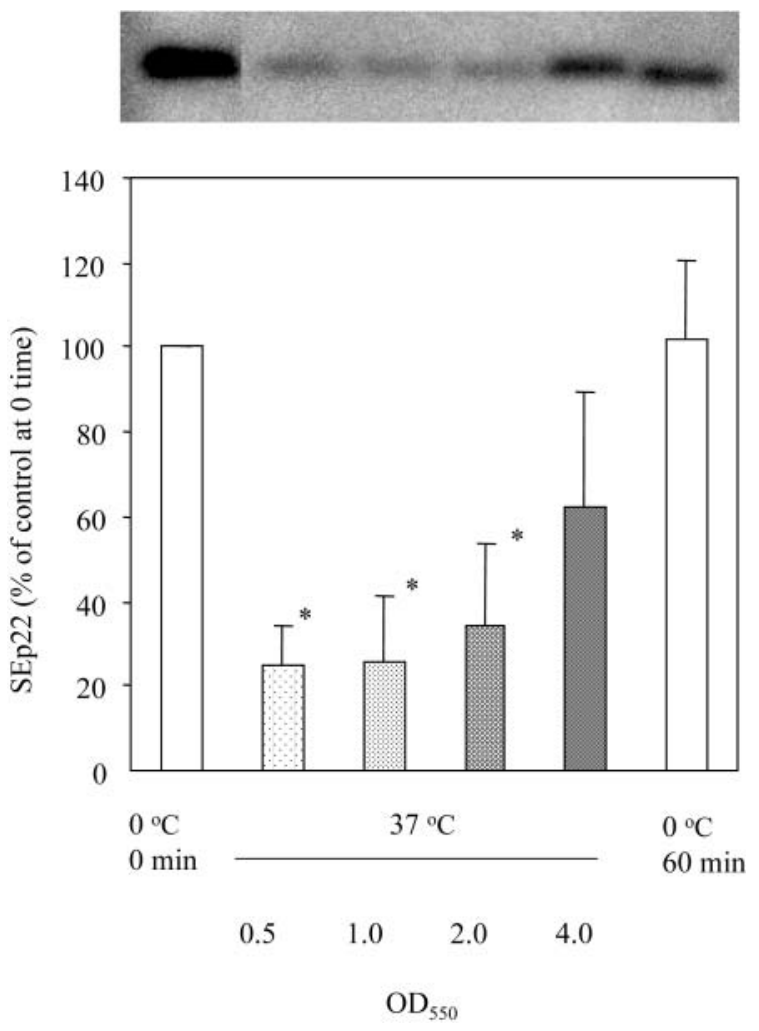

Fig. 4. Effects of cell density in the culture on the degradation of SEp22. Experiments were performed as described in the legends to Figs. 2 and 3, except the conditions for the cell density $\left(\mathrm{OD}_{550}\right)$ of stationary SE for re-incubation varied from 0.5 to $4.0 \mathrm{OD}_{550}$ at $37^{\circ} \mathrm{C}$ for $60 \mathrm{~min}$. On the right side is the negative control incubated at $0^{\circ} \mathrm{C}$ for $60 \mathrm{~min}$ at $\mathrm{OD}_{550}=1.0$. The upper figure shows a representative result of western blotting and the lower one, relative amounts of SEp 22 protein analyzed from three independent experiments, shown as means $\pm \mathrm{SD},{ }^{*} P \leq 0.05$ by Student's $t$-test, compared with the control at $0^{\circ} \mathrm{C}$, at 0 time.

level with time. These results show that SEp22 is temperature-dependently degraded in fresh medium during incubation.

We next estimated the effect of cell density on the degradation of SEp22. When stationary phase bacteria showing $\mathrm{OD}_{550}=0.5,1.0,2.0$ or 4.0 were cultured in fresh medium at $37^{\circ} \mathrm{C}$ for $60 \mathrm{~min}$, SEp22 was degraded almost entirely at $\mathrm{OD}_{550}=0.5$ and 1.0 , while it remained in significant quantities at $\mathrm{OD}_{550}=2.0$ or 4.0 (Fig. 4). Under the conditions of incubation of SE grown to the stationary phase described in the legend of Fig. 2, SEp22 disappeared much more rapidly from the cells during incubation at $\mathrm{OD}_{550}=0.05$ than at $\mathrm{OD}_{550}=0.5$ or 1.0 (Figs. 3, 4; precise data not shown). Therefore, the degradation of SEp22 proceeds more rapidly in low density bacteria than in high density ones.

\section{DISCUSSION}

SE has been one of the most causative bacteria of food-borne diseases and the accurate detection of the pathogenic bacteria is important for the prevention of food poisoning. SE has several virulence factors whose detection has been dependent on genetic analyses like PCR $(11,14)$. For their detection, the invA gene and $s p v C$ gene have been most commonly used as markers (6). Dps is the DNA-binding protein from starved cells, and is one of the most abundant proteins in stationaryphase Escherichia coli $(1,4)$. We isolated and characterized SEp22 in SE from poultry farms, which had recently been identified with Salmonella Dps (Amano et al., manuscript in preparation).

In this study, we showed that not only the SEp22(+) strain but also the SEp22 (-) strain have the same sep22 gene, and suggest that the expression of SEp22 through the growth phases was both transcriptionally regulated for induction and post-translationally regulated for reduction. The results of growth phase-dependent expression of SEp22 suggest coordinated expression of $\sigma^{38}$ and SEp22 mRNA through regulation of RNA polymerase activity (Fig. 2). As for Dps in E. coli, its expression was shown to be regulated by the stationaryphase sigma-factor, RpoS ( $\sigma^{38}$ ), and OxyR and IHF (4). As E. coli enters the stationary phase, more than 180,000 Dps molecules were reported to be accumulated within a single organism, making Dps the most abundant protein in the cell $(1,3,4,10,15)$. These reports seem to be in good agreement with our results for SEp22 in the present study. However, it is not known whether or not a threshold SEp22 amount determines the pathogenicity of Salmonella in the mouse. In our preliminary experiments, expression of very low amounts of SEp22 protein in environmental isolates including $\mathrm{SE} \mathrm{Cl \# 16-1}$ (Fig. 1) failed to show pathogenicity to mouse, while wild-type, SEp22 (+) strain including SE Cl\#15-1 (Fig. 1) showed very strong virulence. We performed the experiments using sep22-defective mutants originated from SE Cl\#15-1, a pathogenic parental strain, and showed that SEp22 expression is closely correlated with pathogenicity of Salmonella to mice (12, 13, Amano et al., manuscript in preparation). Further studies are in progress with revertants to one of the sep22-defective mutants to examine whether or not higher or moderate expression of SEp22 protein might recover the pathogenicity.

The results shown in Figs. 3 and 4 imply the degradation of SEp22 is regulated by some kind of cellular metabolism in fresh medium, because energy 
metabolism in the bacteria is active when cultured at low cell density due to good aeration, while it becomes reduced in bacteria cultured at high cell density.

The presence of Dps homologs in a wide variety of microorganisms, though with molecular divergence, suggests their importance for microorganisms' survival under many kinds of stressful environments. In most organisms Dps serves as an iron-binding protein and protects the organism from oxygen stresses $(7,8,10,15)$. In addition, Halsey et al. reported the contribution of $d p s$ to Salmonella stress resistance, survival in macrophages, and virulence in mice (7). Previously, we reported that the expression of SEp22 protein was closely related to the virulence of $\operatorname{SE}(12,13)$. In this study, we showed that the expression of SEp 22 protein was transcriptionally regulated probably through $\sigma^{38}$ and was regulated by growth phases (Figs. 1, 2), and that the degradation of SEp22 was influenced by temperature and cell-density (Figs. 3, 4), suggesting the requirement of energy metabolism in the degradation of SEp22.

The results of the present study might provide some clues for clarifying the relationship between the regulatory mechanisms underlying the pathogenicity of Salmonella to the host and those underlying the survival and growth of Salmonella in various environments through SEp22 expression. Further studies are now in progress for improving the immunological detection methods for a rapid and sensitive assay of SEp22 which would help in the prevention of Salmonella food poisoning.

Acknowledgements. This work was supported by grants from the Japan Health Sciences Foundation (KH51050, KH51043), and by a Grant-in-Aid for the promotion of Science (15590117) and a Grant-in-Aid for High Technology Research, from the Ministry of Education, Culture, Sports, Science and Technology of Japan.

\section{REFERENCES}

(1) Ali AT, Iwata A, Nishimura A, Ueda S, Ishihama A. 1999. Growth phase-dependent variation in protein composition of the Escherichia coli. J Bacteriol 181: 6361-6370.

(2) Allen-Vercoe E, Dibb-Fuller M, Thorns C, Woodward M. 1997. SEF17 fimbriae are essential for convoluted colonieal morphology of $S$. enteritidis. FEMS Microbiol Lett 153: 33-42.

(3) Almiron M, Link AJ, Furlong D, Kolter R. 1992. A novel DNA-binding protein with regulatory and protective roles in starved Escherichia coli. Genes Dev
6: $2646-2654$.

(4) Alutuvia S, Almiron M, Huisman G, Kolter R, Storz G. 1994. The dps promoter is activated by OxyR during growth and by IHF and sigma $\mathrm{S}$ in stationary phase. Mol Microbiol 13: 265-272.

(5) Centers for Disease Control and Prevention 1996. Outbreak of Salmonella serotype enteritidis infection associated with consumption of raw shell eggs - United States. 1994-1995. Mor Mortal Wkly Rep 45: $737-$ 742.

(6) Cheng-Hsun C, Jonathan TO. 1996. Rapid identification of Salmonella serovars in faces by specific detection of virulence genes, invA and $s p v C$, by enrichiment broth culture-multiplex PCR combination assay. J Clin Microbiol 34: 2619-2622.

(7) Halsey TA, Vazquez-Torres A, Gravdahl DJ, Fang FC, Libby SJ. 2004. The ferritin-like Dps protein is required for Salmonella enterica serovar Typhimurium oxidative stress resistances and virulence. Infect Immun 72: 1155-1158.

(8) Ishikawa T, Mizunoe Y, Kawabata S, Takade A, Harada M, Wai SN, Yoshida S. 2003. The iron-binding protein Dps confers hydrogen peroxide stress resistance to Campylobacter jejuni. J Bacteriol 185: 1010-1017.

(9) Laemmli UK. 1970. Cleavage of structural proteins during the assembly of the head of bacteriophage T4. Nature 227: 680-685.

(10) Sudha N, Steven EF. 2004. Dps protects cells against multiple stress during stationary phase. J Bacteriol 186: 4192-4198.

(11) Tada J, Ohashi T, Nishimura N, Shirasaki Y, Ozaki H, Fukushima S, Takano J, Hishibuchi M, Takeda Y. 1992. Detection of thermostable direct hemolysin-gene $(t d h)$ and the thermostable direct hemolysin-related hemolysin gene (trh) of Vibrio parahaemolyticus by polymerase chain reaction. Mol Cell Probes 6: $477-$ 487.

(12) Terai S, Murayama T, Karahashi T, Amano F. 2003. DNA-binding and modification of DNase I activity by Salmonella SEp22, a novel pathogenicity-related protein identical to Salmonella Dps. Seikagaku 75: 805.

(13) Terai S, Yamasaki M, Igimi S, Amano F. 2004. Growth phase-dependent expression of a pathogenicity-related SEp22 protein, Salmonella Dps, in an environmental isolate Salmonella Enteritidis. Seikagaku 76: 847.

(14) Widjojoatmodjo MN, Fluit AC, Torensma R, Verdonk GPHT, Verhoef J. 1992. The magnetic immuno polymerase chain reaction assay for direct detection of Salmonellae in fecal samples. J Clin Microbiol 30: 3195-3199.

(15) Wolf SG, Frenkiel D, Arad T, Finkel SE, Kolter R, Minsky A. 1999. DNA protection by stress-induced biocrystallization. Nature 400: 83-85. 